\title{
EDITORIAL
}

\section{EDUCACIÓN RELIGIOSA EN LATINOAMERICA}

\author{
ENSINO RELIGIOSO NA AMÉRICA LATINA \\ RELIGIOUS EDUCATION IN LATIN AMERICA
}

Elcio Cecchetti elcioc@unochapeco.edu.br

Jose Mario Méndez Méndez jmariomendez@gmail.com

\author{
Revista do Programa de Pós-graduação em Educação da Unochapecó | ISSN 1984-1566 \\ Universidade Comunitária da Região de Chapecó | Chapecó-SC, Brasil \\ Como referenciar este artigo: CECCHETTI, E.; MÉNDEZ, J. M. M. Editorial: Ensino Religioso na \\ América Latina. Revista Pedagógica, Chapecó, v. 20, n. 44, p. 7-11, mai./ago.
}

REVISTA PEDAGÓGICA

Elvolumen20, número44, dela Revista Pedagógica, aborda el tema de la Educación Religiosa en Latinoamérica. Ese es un elemento complejo y polémico que demarca los contextos educativos desde el proceso colonizador. De hecho, inicialmente la instrucción religiosa fue un arma ideológica utilizada para convertir los pueblos nativos de nuestra Abya Yala en los tiempos de invasión cristiana europea. Posteriormente fue un instrumento de colonización del imaginario de los demás grupos y pueblos subyugados bajo el padrón eurocéntrico y cristiano de ser, pensar, hacer y vivir.

Actualmente, a pesar de las transformaciones sociales generadas por la incorporación político-jurídica del principio de laicidad y de la consecuente separación entre los poderes políticos y religiosos, la instrucción religiosa confesional sigue existiendo en grande parte de los sistemas educativos, con evidente desprecio y desconocimiento de la diversidad religiosa y la pluralidad cultural que constituye a las sociedades contemporáneas.
En las últimas décadas, el crecimiento de la desigualdad, de la exclusión social y de la injusticia cultural en Latinoamérica y el Caribe provocaron el "despertar" de muchísimas personas, grupos y movimientos sociales que se pusieron en marcha para exigir cambios en diferentes esferas sociales, incluyendo los sistemas educativos. Como resultado, creció la convicción de que ya no es posible aceptar que espacios públicos como la escuela sean palco de adoctrinamiento religioso, político, ideológico o de cualquiera otra naturaleza.

La diversidad cultural y religiosa requiere la promoción de procesos educativos interculturales, capaces de reconocer y acoger las diferencias, en la perspectiva de los derechos humanos. Por ello, es necesario repensar la Educación Religiosa con la finalidad de superar la colonialidad del saber, ser y vivir, así como promover relaciones interculturales entre distintas perspectivas religiosas y no religiosas. 
Afortunadamente estamos asistiendo al surgiendo de interesantes iniciativas orientadas a la superación de la Educación Religiosa confesional en distintos contextos latinoamericanos y caribeños. Por ejemplo, destaca el trabajo que viene realizando el Foro Nacional Permanente de Educación Religiosa (FONAPER) de Brasil, que desde 1995 proponeal Estadolaimplementación deuna Educación Religiosa que proporcione el abordaje de los conocimientos religiosos y culturales desde una perspectiva científica, a la luz de las Ciencias de las Religiones, con el fin de asegurar el respecto a la libertad de consciencia y creencia, por medio del ejercicio del diálogo y de la ciudadanía. En Chile, la Red Interreligiosa Latinoamericana de Educación para la Paz (RILEP) junto con el recién creado FONAPER Chile están proponiendo cambios en la estructura educativa chilena, que hasta ahora se imita a ofrecer clases de religión católica o evangélica. En Costa Rica, la Escuela Ecuménica de Ciencias de la Religión de la Universidad Nacional (EECR/UNA) y la Asociación Foro de Educación Religiosa (ASOFER) promueven el debate tendiente repensar interculturalmente la educación religiosa en las escuelas públicas costarricenses.

Ante tal panorama, la Revista Pedagógica invitó a quienes se ocupan de este tema a compartir trabajos en los cuales pudieran describir el contexto de la Educación Religiosa en sus países, así como las experiencias pedagógicas orientadas a superar las convencionales clases confesionales a partir de episte-metodologías interculturales y decoloniales. Como resultado, hemos tenido la feliz participación de destacados autores y autoras que, desde Brasil, Costa Rica y Chile, enviaron sus aportes a través de los siguientes artículos:

El primero de ellos se titula Educación en Clave Interreligiosa: Conocimiento-Otro, Identidad y Alteridad como Marco Pedagógico Crítico, de Nicolas Panotto. El autor propone la resignificación del lugar de la Educación Religiosa en América Latina desde una cosmovisión plural y descolonial de lo educativo, como un aporte a la construcción de un espacio democrático, donde la noción de diálogo, alteridad y conocimientootro son elementales para desarrollar un locus pedagógico crítico.

En segundo artículo es de Maria Cecilia Garcez Leme: Hacia una Educación Religiosa Generadora de Convivialidad y Respeto en las Diversidades. A través de la observación de la realidad costarricense y de un análisis bibliográfico, la autora resalta la importancia que adquieren los procesos educativos para el ejercicio del diálogo y la convivencia respetuosa. Este reto se presenta de manera especial en Costa Rica, donde la religión católica sigue siendo la religión oficial del Estado y los planes curriculares no contemplan satisfactoriamente las exigencias de un escenario pluricultural y multirreligioso. Para María Cecilia, el desarrollo de una epistemología 
indócil y la implementación de metodologías relacionales son los principales desafíos para la Educación Religiosa en la actualidad.

Repensar la Educación Religiosa en sociedades plurales: la formación profesional de docentes de educación religiosa en la Universidad Nacional, de José Mario Méndez Méndez, es el tercer artículo. En él se describe cómo la Escuela Ecuménica de Ciencias de la Religión acogió el desafío de repensar la educación religiosa a partir de la diversidad cultural y religiosa de Costa Rica, y emprendió la tarea de revisar desde la perspectiva intercultural el plan de estudios del Bachillerato en Enseñanza de la Religión. De esa forma, espera contribuir a la formación de docentes capaces de promover procesos educativos en los que las diferentes espiritualidades, creencias y tradiciones religiosas no sean un problema, sino una ocasión para el aprendizaje y un estímulo para la convivencia.

Seguidamente, José Carlos da Silva en su trabajo titulado O Currículo e o Ensino Religioso na BNCC: reflexões e perspectivas, analiza los retos y perspectivas de la Educación Religiosa en Brasil a partir de su reciente incorporación como área del conocimiento en la Base Nacional Curricular Común (BNCC).

El quinto artículo, de la autora Tania Alice de Oliveira, titulado A influência das políticas públicas na formação do professor brasileiro e sua relação com o Ensino Religioso, discute las políticas públicas dirigidas a la formación del profesor brasileño enfatizando su relación con los docentes de Educación Religiosa. Pretende mostrar la relevancia de las políticas públicas en ese tema para asegurar la formación de una sociedad plural y laica, que - por lo tanto - es formación para la ciudadanía.

El último artículo del dosier es de Hanzel José Zúñiga Valerio, titulado Fundamentalismos en las aulas: las "generaciones" de docentes de Religión en Costa Rica y sus aproximaciones a la Biblia. El autor analiza las perspectivas bíblicas que diferencian posibles grupos en el cuerpo de docentes de Educación Religiosa en Costa Rica. Según él, estos grupos de docentes tienen distintas formas de auto-percibirse y de aproximarse al texto bíblico. En la mayoría de los casos, la lectura de la Biblia que realizan está marcada por el biblicismo y/o por el integrismo respecto al Magisterio Católico Romano, lo que dificulta la labor de quienes, de forma minoritaria y aislada, proponen una utópica "cuarta generación" que dé lugar a una Educación Religiosa verdaderamente interreligiosa.

Inaugurando la Sesión de los artículos de demanda continua, los autores Raphael Mota Guilarducci, Lígia Martha Coelho y Alessandra Victor do Nascimento Rosa en Políticas Federales de Educación en Tiempo Integral: ¿el golpe en la formación? analizan los programas federales de extensión de la jornada escolar conocidos en Brasil como "Mais Educação" y "Novo Mais 
Educação". Los autores sostienen que el golpe de Estado ocurrido en el 2016 alcanzó a la Educación, y se materializó en propuestas de educación inspiradas en una concepción productivista y economicista, contribuyendo, cada vez más, a la construcción de ciudadanos carentes de formación crítica.

En Escuela Sin Partido y las Implicaciones para la Democratización de la Educación, Paula Valim de Lima y Vera Maria Vidal Peroni discuten cómo el movimiento que intenta combatir el adoctrinamiento político e ideológico en las escuelas crea mecanismos de censura a los profesores vinculados a una determinada propuesta de educación y de sociedad. A partir del análisis, las autoras concluyen que Escuela Sin Partido es un movimiento esencialmente contradictorio y que busca romper con la posibilidad de construcción de una educación emancipadora, vinculada a los valores sociales, políticos y culturales existentes en la diversidad.

Seguidamente, Sherlon Cristina De Bastiani y Lucas Andres Arbage abordan el tema de las Políticas para Expansión y Democratización del Acceso a la Educación Superior en el Escenario Brasileño. Tienen por objetivo entender los conceptos de expansión y democratización del acceso a la educación superior, así como identificar las políticas claves que favorecieron esos procesos y reflexionar sobre la importancia del tema en el contexto brasileño.

El décimo artículo, Especies Amenazadas y la Educación Ambiental: Conocimiento de Estudiantes sobre el Loro Vináceo, tiene por autoras a Nádia Kroth, Angélica Soligo Cassol y Eliara Solange Müller. Según ellas, para que las acciones de educación ambiental sean efectivas es fundamental percibir cómo los individuos conocen y perciben el mundo natural que los rodea. Con el fin de entender si el contacto con ambientes naturales interfiere en el aprendizaje, investigan el conocimiento del estudiantado sobre la especie Amazona vinacea.

El siguiente artículo es Modelos Didácticos como Estrategia Investigativa y Colaborativa para la Enseñanza de Botánica, de las autoras Viviana Borges Corte, Fernanda Guimarães Saraiva e Idalina Tereza de Almeida Leite Perin. Tomando en consideración la desmotivación de los alumnos en las clases de Biología, se desarrolló un proyecto de investigación liderado por los estudiantes de una escuela pública de enseñanza media en el municipio de Vitória, provincia de Espírito Santo, en Brasil. Los modelos didácticos fueron entonces elaborados por los alumnos de forma colectiva y colaborativa, lo que provocó una importante estrategia motivadora, e hizo que las clases fueran más participativas, las relaciones más horizontales y capaces de facilitar el aprendizaje.

Seguidamente Eduard Angelo Bendrath, Andreia Paula Basei y Jessica Latchuk Frederico abordan la Gestión Educacional y su Relación con la Oferta 
de Actividades Complementarias Curriculares. El objetivo del estudio fue comprender cómo el Programa de Actividades Curriculares Complementarias desarrollado en una ciudad del estado del Paraná, Brasil, posibilita la mejora de la calidad educativa, teniendo como foco de observación el papel del gestor en la conducción de las acciones.

Cerrando esta edición, Rosemery C. Petter y Cristiano Maciel proponen un Análisis de la Producción Científica de Tesis y Disertaciones acerca de la Institucionalización de la Educación a Distancia en el período de 2006 a 2016 . El trabajo tiene como objetivo presentar un panorama general de la producción científica sobre la institucionalización de la Educación a Distancia, realizada en el período de 2006 a 2016. Los resultados revelan que todavía son pocas las investigaciones que tratan del tema y que más de la mitad de ellas fueron defendidas en Programas de Postgrado en el área de Educación.

Considerando la diversidad de temas, autores y contextos, les invitamos a hacer la lectura, el diálogo y el debate con los artículos presentados.

Elcio Cecchetti

(UNOCHAPECÓ/Brasil)

Jose Mario Méndez Méndez

(UNA/Costa Rica)

Editores de esa edición 